\title{
A METAFUNÇÃO TEXTUAL E OS RECURSOS DE IDENTIFICAÇÃO EM MEMORIAL DE LEITURA
}

\author{
Débora Plocharski Haag \\ Lucia Rottava
}

Submetido em 30 de abril de 2019.

Aceito para publicação em 30 de julho de 2019.

Cadernos do IL, Porto Alegre, n. ${ }^{\circ}$ 59, outubro. p. 201-219.

\section{POLÍTICA DE DIREITO AUTORAL}

Autores que publicam nesta revista concordam com os seguintes termos:

1. Os autores mantêm os direitos autorais e concedem à revista o direito de primeira publicação, com o trabalho simultaneamente licenciado sob a Creative Commons Attribution License, permitindo o compartilhamento do trabalho com reconhecimento da autoria do trabalho e publicação inicial nesta revista.

2. Os autores têm autorização para assumir contratos adicionais separadamente, para distribuição não exclusiva da versão do trabalho publicada nesta revista (ex.: publicar em repositório institucional ou como capítulo de livro), com reconhecimento de autoria e publicação inicial nesta revista.

3. Os autores têm permissão e são estimulados a publicar e distribuir seu trabalho online (ex.: em repositórios institucionais ou na sua página pessoal) a qualquer ponto antes ou durante o processo editorial, já que isso pode gerar alterações produtivas, bem como aumentar o impacto e a citação do trabalho publicado.

4. Os autores estão conscientes de que a revista não se responsabiliza pela solicitação ou pelo pagamento de direitos autorais referentes às imagens incorporadas ao artigo. A obtenção de autorização para a publicação de imagens, de autoria do próprio autor do artigo ou de terceiros, é de responsabilidade do autor. Por esta razão, para todos os artigos que contenham imagens, o autor deve ter uma autorização do uso da imagem, sem qualquer ônus financeiro para os Cadernos do IL.

\section{POLÍTICA DE ACESSO LIVRE}

Esta revista oferece acesso livre imediato ao seu conteúdo, seguindo o princípio de que disponibilizar gratuitamente o conhecimento científico ao público proporciona sua democratização.

http://seer.ufrgs.br/cadernosdoil/index

Terça-feira, 29 de outubro de 2019. 


\title{
A METAFUNÇÃO TEXTUAL E OS RECURSOS DE IDENTIFICAÇÃO EM MEMORIAL DE LEITURA
}

\author{
THE TEXTUAL METAFUNCTION AND \\ IDENTIFICATION RESOURCES IN READING \\ MEMORIAL
}

\author{
Débora Plocharski Haag* \\ Lucia Rottava*
}

\begin{abstract}
RESUMO: este artigo objetiva analisar como o fluxo de informação de um texto é construído e como são realizados a apresentação, o rastreamento e a manutenção dos participantes em textos escritos, em Língua Portuguesa, por ingressantes do curso de Letras. Orientado teoricamente pela Linguística Sistêmico-Funcional, centra-se no recurso semântico-discursivo identificação (MARTIN; ROSE, 2007) $e$ realiza, como procedimento metodológico, análise descritivo-qualitativa em um texto escrito, cujo gênero é o Memorial de Leitura, produzido por um aluno do primeiro semestre de graduação em Letras. Os resultados apontam para uma compreensão acerca da utilização da identificação no gênero Memorial de Leitura e para um possível trabalho de utilização consciente desse recurso com a finalidade de aprimoramento da escrita.
\end{abstract}

PALAVRAS-CHAVE: Memorial de Leitura; Linguística Sistêmico-Funcional; metafunção textual; identificação.

RESUMEN: este artículo objetiva analizar cómo se construye el flujo de información de un texto y cómo son realizados la presentación, el seguimiento y la manutención de los participantes en los textos escritos, en portugués, por ingresantes de la carrera de Letras. Orientado teóricamente por la Lingüística Sistémico-Funcional, se centra en el recurso semántico-discursivo identificación (MARTIN; ROSE, 2007) y realiza, como procedimiento metodológico, análisis descriptivo-cualitativo en un texto escrito, cuyo género es el Memorial de Lectura, producido por alumno, del primer semestre de graduación en Letras. Los resultados apuntan a una comprensión acerca de la utilización de la identificación en el género Memorial de Lectura y para un posible trabajo de uso consciente de ese recurso con la finalidad de perfeccionamiento de escritura.

PALABRAS-CLAVE: Memorial de Lectura; Lingüística Sistémico-Funcional; metafunción textual; identificación.

\section{Introdução}

Este artigo, embasado na Linguística Sistêmico-Funcional hallidyana (HALLIDAY, 2017), situa-se no estrato semântico e aborda o sistema semântico-discursivo denominando IDENTIFICAÇÃO (MARTIN; ROSE, 2007) ${ }^{1}$.

\footnotetext{
* Mestra pela Universidade Federal do Rio Grande do Sul, deboraphaag@gmail.com

** Professora na Universidade Federal do Rio Grande do Sul, pós-doutora pela University of London, luciarottava@yahoo.com.br

${ }^{1}$ Martin e Rose (2007) utilizam os termos texto e discurso sem fazer uma diferenciação entre eles, uma vez que têm um olhar semântico-discursivo para o seu objeto de análise. Neste artigo os dois termos são utilizados. No entanto, optou-se por utilizar o termo texto ao se fazer referência à sala de aula e à
} 
Trata-se de um recurso utilizado para acompanhar como as pessoas e objetos são inseridos e rastreados ao longo de um texto, como são mantidas as identidades destes participantes e coisas no discurso e como se sabe a quem ou a que uma expressão se refere ao longo de um texto.

A orientação pela Linguística Sistêmico-Funcional (LSF) permite olhar para as manifestações linguísticas sob diferentes dimensões, tomando o texto como objeto de análise. Assim, considerando o contexto acadêmico de produção de textos escritos, propõe-se olhar para o texto em seu contexto social, entendendo-o como uma manifestação sociocultural (MARTIN; ROSE, 2007). Para tanto, são considerados os processos sociais que envolvem a produção: quem produziu o texto, a cultura em que este sujeito está inserido, para quem o texto foi produzido, por que ele foi produzido e qualquer outro fator que possa influenciar esta produção.

O contexto acadêmico é considerado um contexto social da produção escrita, pois nele os ingressantes trazem suas experiências no texto, sinalizadas por diferentes recursos linguísticos, dentre os quais estão os recursos semântico-discursivos (MARTIN; ROSE, 2007). Esses recursos permitem olhar para a linguagem sob a perspectiva da gramática, do discurso e do contexto social, e, simultaneamente, permitem observar a representação das experiências e a maneira como são organizadas as informações em um texto (seja ele oral ou escrito) (MARTIN; ROSE, 2007). Neste artigo, o foco recai sobre como as informações são organizadas no texto, de maneira que se possa perceber o papel dos participantes nessa construção. Para isso, o olhar está direcionado principalmente para os significados semântico-discursivos, mas com a léxico-gramática e o contexto social como suporte para a compreensão do discurso.

Assim, o enfoque deste artigo é nos recursos que dizem respeito à organização do texto, entendidos pela LSF como recursos da metafunção textual, dentre eles, o recurso de IDENTIFICAÇÃO em textos produzidos em Língua Portuguesa por acadêmicos do curso de Letras. A escolha deve-se por se tratar de recurso de importância para o ensino de escrita e compreensão leitora. O propósito é analisar, com base no trabalho realizado por Martin e Rose (2007), como são realizados a apresentação, o rastreamento e a manutenção dos participantes em um exemplar de texto escrito por ingressante do curso de letras, em Língua Portuguesa. O objetivo é utilizar como ferramenta de análise o recurso de IDENTIFICAÇÃO para analisar a organização de texto escrito por acadêmico do curso de Letras, em Língua Portuguesa.

Este artigo está organizado em quatro seções, além desta introdução. Apresenta-se uma reflexão teórica a respeito da relação entre a metafunção textual e os recursos semântico-discursivos, seguida do desenho do estudo, análise do texto com base no recurso de IDENTIFICAÇÃO, e finaliza-se com as considerações finais e referências bibliográficas.

\section{A metafunção textual e o recurso semântico-discursivo de IDENTIFICAÇÃO}

A metafunção é um conceito complexo que mostra a relação entre a organização da linguagem e a função desempenhada por ela. As funções da língua, categorias semânticas denominadas na LSF de registros, não são universais e variam de acordo com a necessidade de uso nas distintas comunidades linguísticas. Por não ser possível

produção dos estudantes, reservando-se o uso do termo discurso para explicações referentes ao nível semântico-discursivo da língua. 
enumerar os usos da língua, a noção de metafunção amplia o conceito de função, relacionando os usos sociais com o sistema linguístico e tratando de funções mais abstratas, que estão presentes em todas as línguas (HALLIDAY; MATTHIESSEN, 2014; GHIO; FERNANDEZ, 2008).

Entende-se que a língua é organizada internamente pelas funções sociais que realiza (MARTÍNEZ LIROLA, 2007), que correspondem a três metafunções: ideacional, interpessoal e textual, como sendo componentes funcionais da gramática das línguas (HALLIDAY; HASAN, 1985). Do ponto de vista analítico, quando se quer compreender ou fazer a análise de um texto, pode-se fazê-lo em um nível semânticodiscursivo ou no nível da oração, nível léxico-gramatical. Tanto em uma opção como na outra serão encontrados os recursos linguísticos referentes às três linhas metafuncionais unificados/combinados. Quando se olha o texto no nível da léxico-gramática, a unidade de análise é a oração e seus elementos. Quando o foco é o nível semântico-discursivo, os recursos léxico-gramaticais são utilizados para identificar significados para além das orações, olhando para o texto como uma unidade de significado, interpretando o discurso (MARTIN; ROSE, 2007).

Martin e Rose (2007, p. 4, tradução nossa) ${ }^{2}$ esclarecem que "a atividade social, o discurso e a gramática são diferentes tipos de fenômenos, operando em diferentes níveis de abstração". Assim, olhar para uma manifestação linguística do ponto de vista da LSF requer que se entenda que gramática, discurso e contexto social estão interligados, conforme a Figura 1:

Fonte: adaptado (HALLIDAY; MATTHIESSEN, 2014).

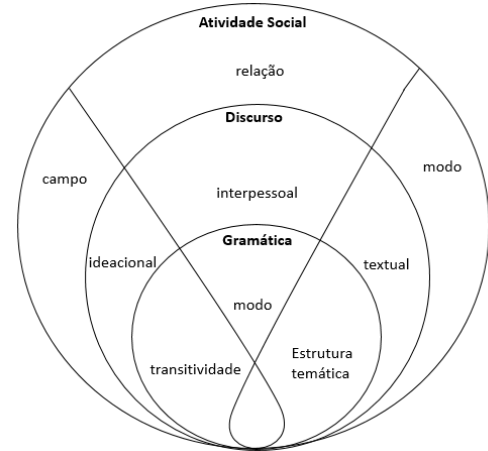

Figura 1 - Interconexão/relação entre gramática, discurso e atividade social (contexto de situação) na composição da manifestação linguística e a relação entre a composição de seus elementos.

Como ilustrado na Figura 1, a metafunção ideacional está ligada ao campo, no nível do contexto de situação, e expressa a experiência, o conteúdo de uma cultura ou de um indivíduo em relação ao mundo que o rodeia ou ao seu mundo interior. É ela que demonstra a capacidade do ser humano de construir significados e representar experiências por meio da linguagem. A metafunção ideacional é parte do sistema semântico da língua, no entanto, pode ser estudada no nível em que é realizada, a léxico-gramática. Para isso, os componentes léxico-gramaticais observados, especificamente do subcomponente experiencial, são os processos, participantes e circunstâncias, integrantes do sistema gramatical chamado sistema de transitividade. Já

${ }^{2}$ Original em inglês: Social activity, discourse and grammar are different kinds of phenomena, operating at different levels of abstraction. 
o subcomponente lógico oferece os recursos para formar os diversos tipos de complexos oracionais (FUZER; CABRAL, 2014). Por sua vez, se analisada do ponto de vista do sistema semântico-discursivo, essa metafunção contempla os recursos semânticos ideação, que trata de como a experiência é interpretada no discurso e como os elementos discursivos são construídos e relacionados entre si; e conjunção, recurso ligado à função lógica da linguagem. O recurso conjuntivo está relacionado à conectividade entre os processos, adicionando, comparando, sequenciando ou explicando-os (MARTIN; ROSE, 2007).

A metafunção interpessoal está ligada ao componente situacional relação, que lida com os participantes envolvidos na interação. $O$ estudo desta metafunção pode levar à compreensão dos papéis e identidades sociais assumidos pelos participantes da interação no discurso. Léxico-gramaticalmente, a metafunção interpessoal da linguagem é realizada pelo sistema de Modo. Por meio dele, é possível observar a maneira com que o falante/escritor organiza sua oração para interagir. Por sua vez, o sistema semântico-discursivo de significados interpessoais traz dois recursos utilizados na linguagem: a avaliatividade e a negociação. O recurso da avaliatividade é usado para negociar nossas relações sociais, utilizando expressões que explicitam ao ouvinte como nos sentimos em relação a coisas ou a pessoas. Já o recurso da negociação, refere-se a como os falantes assumem e atribuem papéis, realizando trocas, negociando atitudes, sendo percebidos nas declarações, perguntas, ofertas e exigências de bens e serviços trocadas entre os participantes do discurso (MARTIN; ROSE, 2007).

A metafunção textual, foco deste artigo, está relacionada à composição/construção do texto, sendo responsável, nesta composição textual, pela organização das funções experiencial e interpessoal em um todo coesivo e coerente, possibilitando assim a realização de trocas de informações entre o falante e o ouvinte (HALLIDAY; MATTHIESSEN, 2014).

A despeito da abordagem dos recursos textuais coesivos apresentados por Halliday e Matthiessen (2014), Martin e Rose (2007) realizam um trabalho diferenciado, tendo como foco o sistema semântico-discursivo de significado. Para os autores:

[...] o foco está na semântica do discurso, e não na gramática ou no contexto social, porque parece que, embora haja muita análise nos níveis de gramática e gênero acontecendo ao redor do mundo, há uma necessidade crescente e oportunidades crescentes de trabalho que construam pontes de forma sistemática entre esses níveis. Este livro tenta preencher essa lacuna com análises de significados além da oração que faz contato com o contexto social. $^{3}$ (MARTIN; ROSE, 2007, p. 11, tradução nossa).

Os autores trabalham com a perspectiva semântico-discursiva relacionada aos recursos linguísticos de cada uma das metafunções, criando ferramentas adequadas à análise do discurso. Martin e Rose (2007) defendem que o estudo do texto requer que o analista se coloque em um lugar entre os gramáticos e os teóricos sociais, uma vez que, ao tomar o texto como objeto de análise, lida-se com algo maior que a oração e menor

\footnotetext{
${ }^{3}$ Original em inglês: Our focus is on discourse semantics rather than grammar or social context because it seems to us that, while there is a lot of analysis at the levels of grammar and genre going on around the world, there is a growing need and expanding opportunities for work that bridges systematically between these levels. This book attempts to fill that gap with analyses of meanings beyond the clause that make contact with social context.
} 
que uma cultura. Desta forma, tem-se o discurso sob dois pontos de vista, utilizando as ferramentas dos gramáticos para analisar a composição textual e as ferramentas dos teóricos sociais para explicar por que elas significam o que significam (HALLIDAY, 2001). Portanto, Martin e Rose (2007) propõem um olhar para além do conjunto léxico-gramatical proposto por Halliday e Hasan (1976), apresentando um conjunto de sistemas semântico-discursivos em um nível mais abstrato (VIAN JR.; MENDES, 2015). Tais sistemas estão relacionados às funções sociais da linguagem e às metafunções da linguagem, como é possível observar no Quadro 1:

Quadro 1 - Relação entre o sistema semântico-discursivo e as metafunções.

\begin{tabular}{|c|c|c|c|}
\hline \multicolumn{2}{|c|}{ Sistema discursivo } & \multicolumn{2}{|l|}{ Metafuncão } \\
\hline Identificação & Rastrear pessoas e coisas & Textual & Organizar textos \\
\hline Periodicidade & Fluxo de informação & & \\
\hline Negociação & Promover trocas & \multirow[t]{2}{*}{ Interpessoal } & \multirow{2}{*}{$\begin{array}{l}\text { Deflagrar relações } \\
\text { sociais }\end{array}$} \\
\hline Avaliatividade & Negociar atitudes & & \\
\hline Conjunção & Conectar eventos & \multirow[t]{2}{*}{ Ideacional } & \multirow{2}{*}{$\begin{array}{l}\text { Representar a } \\
\text { experiência }\end{array}$} \\
\hline Ideação & Representar a experiência & & \\
\hline
\end{tabular}

Fonte: Martin e Rose (2007), adaptado por Vian Jr. e Mendes (2015).

Em relação à metafunção textual da linguagem, observada no Quadro $1 \mathrm{e}$ foco deste artigo, Martin e Rose (2007) apresentam os recursos de IDENTIFICAÇÃO e PERIODICIDADE como ferramentas da linguagem capazes de realizar uma interlocução entre o discurso, a atividade social e a gramática, por meio da inserção e rastreamento de participantes e do controle do fluxo informacional. Tais recursos, que se classificam como recursos referenciais ${ }^{4}$, contribuem conjuntamente para a organização textual e permitem que o leitor seja capaz de acompanhar o que está sendo dito a qualquer momento do discurso, bem como depreender, através do ritmo do discurso, quais as possibilidades para a sequência desse discurso.

\section{Desenho do estudo e dados analisados}

Este estudo é de natureza qualitativa (DÖRNYEI, 2007), pois a amostra de análise é pequena, uma vez que tem a intenção de ser exaustiva, ou seja, analisa um único texto em profundidade, não em extensão. Ressalta-se que na LSF é nas interações linguísticas que os significados são construídos e, sendo assim, as análises textuais requerem textos autênticos, produzidos nas interações sociais. Desta forma, quando um texto é analisado à luz da LSF, são considerados o contexto em que foi produzido e o propósito para o qual foi escrito (VIAN JR.; IKEDA, 2006). Em acordo com tais asserções, o corpus de análise de onde foi escolhido um exemplar para esta pesquisa é composto por textos que podem ser encontrados no Blog Leitura e Produção Textual (2014-2018, s.p.), que se constitui em um banco de dados coletados de acordo com o

\footnotetext{
${ }^{4}$ Este trabalho não tem o propósito de discutir as diversas acepções da palavra "referência" no estudo do texto. É considerado, apenas, o uso deste termo como compreendido nos estudos realizados por Martin e Rose (2007).
} 
Comitê de Ética em Pesquisa da Universidade Federal do Rio Grande do Sul e faz parte do projeto "A Linguística Sistêmico-Funcional e a Escrita/Reescrita Acadêmica"5.

No blog são armazenados textos de um conjunto de tarefas, que também podem ser referidas como um portfólio de leitura e produção textual (ROTTAVA, 2014). As tarefas foram produzidas por alunos do curso de graduação em Letras da Universidade Federal do Rio Grande do Sul (UFRGS) e coletados desde 2014. Os textos foram escritos no primeiro semestre do curso para a disciplina Leitura e Produção Textual que visa "desvelar o processo de ensino e de aprendizagem, e a reflexão por parte dos aprendizes desse processo" (ROTTAVA, 2014, p. 917), por meio de um método que entende a leitura e a escrita como mecanismos inter-relacionados.

Dentre os textos que compõem o blog, para este artigo, foi selecionado um exemplar da tarefa denominada "Memorial de Leitura", cuja escrita consiste em contar sua própria trajetória de leitura e a interlocução desta com as leituras realizadas na disciplina, discutindo o conceito de leitura.

Na LSF os gêneros seguem a conceituação dada por Martin (2000, p. 5) para quem o gênero é "entendido como processo social, orientado para um fim e desenvolvido em Fases ou Etapas 6". Sob esse viés, o gênero Memorial de Leitura não é um gênero simples, mas misto, que tem por propósitos sociais informar e avaliar. Tais propósitos são normalmente encontrados, respectivamente, nos gêneros autobiografia — da família das histórias —, e no gênero exposições — da família dos gêneros argumentativos (ROTTAVA, 2014, 2017).

Desta forma, as Etapas do gênero Memorial de Leitura alternam-se entre Orientação $\wedge^{\wedge}$ Registro de Estágio, quando estão sendo relatados eventos ocorridos; e Tese $^{\wedge}$ Argumentos ${ }^{\wedge}$ Reiteração de tese quando, com a finalidade de persuadir o leitor, o escritor expõe uma Tese e apresenta argumentos que a sustentem (MUNIZ DA SILVA, 2018). Ainda, segundo Martin e Rose (2007), esse argumento pode conter duas Etapas: $1^{\text {a }}$ ) os fundamentos sobre os quais está argumentando e $2^{\mathrm{a}}$ ) uma conclusão com base nas evidências.

Análises realizadas sob o ponto de vista da LSF permitem que se olhe para diferentes estratos da língua a partir de diferentes pontos de vista. Nesta pesquisa, optou-se por olhar o estrato semântico-discursivo da língua, de onde é possível observar o funcionamento da metafunção textual e compreender como ocorre o processo de organização textual por meio do recurso de IDENTIFICAÇÃO.

\section{IDENTIFICAÇÃO: rastreando participantes em textos escritos em Língua Portuguesa}

A IDENTIFICAÇÃO é um recurso textual "preocupado" em como o discurso faz sentido para o leitor. Para que se possa acompanhar um discurso é preciso que se saiba sobre o que se está falando, ou a que se está referindo em qualquer etapa do discurso. Assim, esse é um recurso utilizado para acompanhar como as pessoas e objetos são inseridos e rastreados ao longo de um texto.

\footnotetext{
${ }^{5}$ Projeto integrado à rede de pesquisa SAL - Systemic, Ambience and Language.

${ }^{6}$ Para fins de distinção no uso dos termos etapa e fase, optou-se por utilizar letra maiúscula ao referir-se às Etapas e Fases do gênero e letra minúscula para o uso geral do termo.

${ }^{7}$ O símbolo significa "seguido por".
} 
De acordo com Martin e Rose (2007), pessoas e coisas (concretas ou abstratas) são identificadas de maneira muito semelhante em um texto. A introdução e o rastreamento dos referentes são ações realizadas através dos recursos de apresentação de referência (presenting), presunção de referência (presuming), posse (possessive) e comparação (comparative). Tais recursos são abordados a seguir, em um único dado desta pesquisa, para que se possa observar como funcionam em textos escritos em Língua Portuguesa.

No Texto A (LEITURA, 2014), foram destacados dois referentes. O Referente 1, que aparece no texto sublinhado, diz respeito ao que é chamado de "Eu narrador". Por sua vez, o Referente 2, que aparece destacado em negrito, faz menção à "leitura". A escolha de tais referentes deve-se ao fato de que estão presentes do início ao fim do texto, diferentemente de outros referentes não retomados pelo autor.

Texto A:

01 Leitura: Do colorido prazer à necessidade

Quando criança, eu não vi a tarefa escolar de aprender as letrinhas e os seus sons como enfadonha ou entediante, ou algo que poderia parecer repetitivo por parte das

05 professoras. Pelo contrário: $\varnothing$ [eu] quis poder entender o mais rápido possível aquele código aparentemente indecifrável que meus pais compreendiam; $\emptyset[\mathrm{eu}]$ ansiei por aprender a ler. Assim, $\underline{\varnothing[\mathrm{eu}]}$ encarei as letras e as palavras como amigas a serem

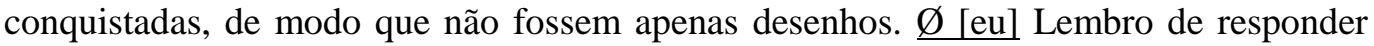
empolgadamente à professora da pré-escola o som que cada letrinha fazia; eu estava

10 impaciente para finalmente decifrar aqueles símbolos que pareciam mágicos!

Segundo Britto (2012), as ações básicas de ler são a decifração do escrito e a compreensão do conteúdo do texto. Aos cinco anos, eu estava começando a tornar-me apta para realizar essas ações: finalmente eu entendera a lógica das letras e $\emptyset$ [eu] conseguia decodificá-las (isto é, entender os sons produzidos por aqueles signos, e

15 consequentemente, seu significado). Quando as tais letras do alfabeto ganharam sentido para mim, o mundo ficou mais doce e colorido: $\emptyset[\mathrm{eu}]$ passei a escrever num diário corde-rosa e podia ler os livros que a professora lia para turma. Meu preferido era um de poesia: A Casa Sonolenta, de Audrey Wood, que contava a história de uma casa onde todos dormiam até serem atrapalhados por uma pulguinha. $\mathbf{O}$ ambiente mágico da

20 leitura havia tomado forma para mim, isto é, ele agora era alcançável, e eu podia explorar aquele universo das palavras. "Aí vou eu!".

A partir daí, foi fácil para que eu criasse gosto por ler. Rottava (2000) afirma que a leitura como prática social "é uma leitura que envolve o propósito de que ler é utilizarse da linguagem para determinado objetivo, bem como para alguém e em certas

25 circunstâncias" (pg 14). Meu objetivo inicial de leitora era o prazer e a descoberta, como antes $\emptyset$ [eul falei, e isso trouxe facilidade ao começo da minha caminhada na leitura, pois não me importava em ter que ler. O incentivo dado neste quesito pelas professoras era entrelaçado a uma obrigação por elas imposta, mas eu não percebia isto. "Vocês têm que retirar um livro na biblioteca, toda semana!" podia parecer, às vezes, uma ordem

30 desnecessária a mente de uma criança, mas geralmente era por mim encarada com deleite: imagine ter centenas de livros a sua disposição, prontos para serem explorados, com suas histórias esperando para serem vividas; que mal havia em ser "obrigada" a escolher um? Afinal, a biblioteca do colégio era um lugar multicolor, preenchida por almofadas vermelhas e azuis aconchegantes, prateleiras cheias de maravilhosos livros

35 esperando para serem desfrutados e criancinhas que percorriam o ambiente de aprendizagem com muita animação. Era o paraíso na Terra. 
Minhas pequenas mãozinhas de menina e meus olhos curiosos selecionavam os

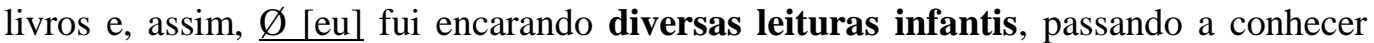
alguns gêneros textuais, suas estruturas e formas de discurso a mim apresentados. Isso

40 foi acrescentando saber ao meu conhecimento textual, que faz parte do conhecimento prévio sobre o qual Kleiman (1995) fala. Se antes eu estava habituada a historinhas cheias de animais fofos, como Ninoca, uma ratinha que vivia numa casa de dobraduras, ou Os Pingos, ratos coloridos que residiam numa floresta, agora eu havia entrado num novo terreno. A coleção Salve-se Quem Puder não tinha as cores fosforescentes das

45 leituras pré-escolares, e sim apresentava tons mais sombreados: era composta por livros de mistério com diversos enigmas a serem resolvidos, o que fazia com que o leitor estivesse extremamente atento a cada página e imagem. Mas era um perigo rápido e ilusionista que eu podia "fechar" (num fechar do livro) a qualquer momento, e então correr para reabraçar a poesia, que continuou a me encantar: A Caixa Mágica de

50 Surpresa, coletânea de poemas de Elias José, por exemplo, brincava com divertidos elementos como piratas, animais, objetos, uma vovó e até um arco-íris. Ah, o belo mundo multicolor ainda estava ali!

Conforme $\underline{\varnothing[\mathrm{eu}]}$ avancei no Ensino Fundamental, me afastei do campo infantil e $\underline{\varnothing}$ [eu] fui iniciada, através da escola e de amigos, na literatura infanto-juvenil. Tons55 pastéis de problemas reais começaram a invadir meu mundo leitor, pois agora os livros refletiam meus conflitos de pré-adolescente, e eu me espelhava nas protagonistas das aventuras para resolvê-los. Eram textos divertidos: Judy Moody, de Megan McDonald, por exemplo, contava a história de uma menina da terceira série um pouco rebelde e deslocada. $\emptyset[$ [eu]Também li O Diário da Princesa, de Meg Cabot, que dizia respeito a

60 uma garota norte-americana comum que, de um dia para o outro, descobria ser uma princesa. Ainda me apaixonei por A Princesinha, de Frances Burnett, livro sobre uma menina abastada que acaba perdendo o pai e toda sua riqueza. Muitos outros títulos também regaram essa minha fase. Estas leituras estavam, sem que eu percebesse, ensinando-me a respeito dos recursos textuais, como a ironia de Judy Moody, a presença

65 de um duplo texto em O Diário da Princesa (onde, no meio do livro, havia rabiscos matemáticos da protagonista Mia) e outras características narrativas.

A partir da sexta série, também, minha professora de português optou por fazer trabalhos com as turmas abordando diferentes gêneros textuais: poesias, publicidades, poemas visuais, receitas, crônicas, notícias, cartas, diários e entre outros. $\emptyset$ [eu] Percebo

70 hoje o quanto isso contribui para que eu tivesse maior facilidade na leitura nos diferentes contextos do dia-a-dia. Como afirmou Kleiman (1995): "Quanto mais conhecimento textual o leitor tiver, quanto mais sua exposição a todo o tipo de texto, mais fácil será sua compreensão, [...] pois o conhecimento das estruturas textuais e de todo tipo de discurso determinará, em grande medida, suas expectativas em relação aos

75 textos" (pg 20). Minha mente, hoje, pode lidar com certa facilidade com diversos tipos de estrutura.

Por fim, chegando quase ao Ensino Médio, debrucei-me na leitura de Senhor dos Anéis, As Crônicas de Nárnia, Dom Casmurro e outras obras. Foi a partir do primeiro ano que $\underline{\varnothing[\mathrm{eu}]}$ passei a buscar obras de maior conteúdo histórico. Minha curiosidade, 80 então, voltou-se para as questões culturais do mundo, e não somente para a busca pela identificação com um personagem ou o entendimento das palavras; $\underline{\varnothing[\mathrm{eu}]}$ percebi que gente de toda parte do planeta tinha seus próprios conflitos. $\emptyset$ [eu] Li livros sobre cultura muçulmana (Prisioneira em Teerã; O Caçador de Pipas; O Livreiro de Cabul), nazismo (Olga; O Refúgio Secreto) e ainda sobre cultura oriental. $\emptyset$ [eu] Estava cada

85 vez mais engajada naquilo que Kleiman fala sobre "fazer da leitura uma atividade caracterizada pelo engajamento e uso do conhecimento, em vez de uma mera recepção passiva" (pg 26). Meu senso tornou-se cada vez mais crítico, e cada nova bagagem de conhecimento que eu adquiria servia para dialogar com as anteriores.

Meus objetivos de leitura foram, em sua maioria, modificando-se durante o Ensino 
90 Médio: a leitura passou a ser dirigida à aprovação em testes escolares. Minha interação com o texto tornou-se mais perceptível. Segundo Rottava (1998), é justamente essa interação que dá sentido a ele. $\underline{\emptyset}$ [eu] Precisei lidar cada vez mais com textos informativos, devido aos estudos relacionados ao vestibular e pesquisas do colégio; $\underline{\varnothing}$ [eu] tinha que selecionar partes do texto e literalmente discuti-las em minha cabeça.

95 Quanto às leituras obrigatórias de Literatura e Português, $\emptyset[\mathrm{eu}$ necessitei estar cada vez mais ciente da trama, dos aspectos linguísticos e abordagem histórica dos livros, pois todos estes pontos caíam em provas. O terceiro ano do Ensino Médio parecia tão chato literariamente falando que muito do que dizia respeito à leitura tornara-se preto e branco, sem prazer e atrativos, ou cinza e sem graça como uma placa de chumbo.

100 Atualmente, no entanto, enquanto $\emptyset[\mathrm{eu}]$ estou cursando a graduação de Letras, a leitura tem se reapresentado a mim como quem pede desculpas. Sim, é verdade que ela não é mais tão colorida ou idealizada como antes, e que $\emptyset$ [ela] se tornou uma necessidade - ler (não somente decifrar os signos, mas também compreender o conteúdo textual) é essencial na grande parte do âmbito profissional, e, para quem cursa uma

105 graduação, é instrumento indispensável para o aprendizado, com tanto material escrito

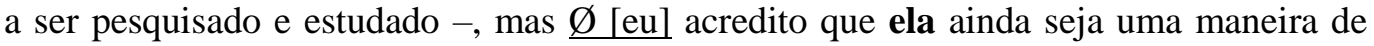
saciar a curiosidade e de exploração do cosmos. $\underline{\varnothing[\mathrm{eu}]}$ Posso até ser obrigada a ler Odisséia para realizar uma prova, por exemplo, mas o $\underline{\varnothing}[\mathrm{eu}]$ faço com bastante prazer, pois ela me apresenta o universo grego de mitologia e é um dos componentes mais

110 importantes da literatura. Neste meu novo mundo quase adulto de leitura, obrigação e prazer se misturam e mesclam, unindo o arco-íris de cores ao preto e branco.

$\emptyset$ [eu] Sei que a minha mente, em algum lugar remoto dentro de si, ainda acredita nas palavras do poema tão amado em minha infância, Caixa Mágica de Surpresa, de Elias José: "Um livro / é uma beleza, / É caixa mágica / só de surpresa. / Um livro /

115 parece mudo, / mas nele a gente / descobre tudo. / Um livro / tem asas / longas e leves / que, de repente, / levam a gente / longe, longe."

No texto, pode ser observado que, de acordo com Martin e Rose (2007), uma pessoa ou coisa é introduzida/apresentada em um texto de forma indefinida, quando se depreende que o leitor/ouvinte não está a par daquilo que está sendo falado. No entanto, quando há a presunção da referência pelo leitor, ou seja, quando o leitor tem conhecimento do elemento que está sendo inserido, mesmo que pela primeira vez, no discurso, é possível utilizar expressões definidas. Esta possibilidade decorre de um contexto compartilhado entre escritor/falante e leitor/ouvinte.

O contexto de escrita dos textos disponíveis no Blog Leitura e Produção Textual, apresentado no desenho do estudo, é fundamental para que se compreenda a maneira como os referentes são inseridos no texto sob análise. Por se tratar de um Memorial de Leitura, o texto é narrado em primeira pessoa, assim, o Referente 1 (sublinhado no texto em análise) é o referente principal e coincide com a identidade do autor do texto, o que faz com que seja inserido no texto sem um determinante. Já o Referente 2 (em negrito no texto em análise) é inserido de forma definida pela expressão a tarefa escolar de aprender as letrinhas (1.03), uma vez que o contexto compartilhado leva o escritor a entender que "leitura" é um referente presumido pelos seus leitores.

Outros referentes são apresentados de forma indefinida, como num diário corde-rosa (1. 16-17), uma casa onde todos dormiam (1. 18-19), uma pulguinha (1. 19), uma leitura (1. 23), uma obrigação (1. 28), um livro na biblioteca (1. 29), uma criança (1. 30), um lugar multicolor (1. 33), uma ratinha, numa casa de dobraduras (1. 42), numa 
floresta (1. 43), num novo terreno (1. 43-44), uma vovó (1. 51), um arco-íris (1. 51), uma menina (1. 58), uma garota norte-americana (1.60), um dia (1. 60), uma princesa (1. 6061), uma menina (1. 61-62), um personagem (1. 81), uma necessidade (1. 102-103), uma graduação (1. 104-105), uma maneira (1. 106).

O esperado, segundo Martin e Rose (2007), é que determinantes indefinidos sejam utilizados quando um referente é inserido pela primeira vez e não há presunção de sua identidade. Já os determinantes definidos serão utilizados quando a identidade do referente já é conhecida. No entanto, Martin e Rose (2007) trazem a possibilidade do uso de determinante indefinido acompanhando um referente já apresentado, o que chamam de "aparente anomalia", como se pode observar no fragmento do texto sob análise, representado no exemplo $(01)^{8}$ :

(01)Quando as tais letras do alfabeto ganharam sentido para mim, o mundo ficou mais doce e colorido: passei a escrever num diário cor-de-rosa e podia ler os livros que a professora lia para turma. Meu preferido era um de poesia: A Casa Sonolenta, de Audrey Wood, que contava a história de uma casa onde todos dormiam até serem atrapalhados por uma pulguinha. (1. 15-19)

No exemplo (01), o referente livro é inserido pela forma genérica os livros (1. 16), que é retomada pelo sintagma mеи [livro] preferido (1. 17), em que o referente é especificado e, depois, é retomado como um [livro] de poesia (1. 17). O que Martin e Rose (2007) querem dizer com "aparente" anomalia é que, verdadeiramente, o artigo indefinido está sendo utilizado para classificar (também poderá ser utilizado para descrever) o referente livro como de poesia, e não para apresentá-lo. A apresentação de referentes com determinante definido, já mencionada nesta seção, também pode ser considerada uma "aparente" anomalia.

Uma vez inserido e apresentado ao leitor/ouvinte, o referente pode ser retomado por expressões determinantes como os artigos definidos, por pronomes, pelo próprio nome e no caso da Língua Portuguesa pelo pronome elíptico. Em relação à forma elíptica, Sippert (2017, p. 70) afirma que o recurso não é abordado por Martin e Rose (2007) porque, na língua inglesa, "este não é um recurso empregado no nível semântico para realizar a função de Tema sujeito". A forma elíptica, na língua inglesa, é utilizada como ferramenta apenas no nível léxico-gramatical, estabelecendo conexões entre elementos textuais (MARTIN; ROSE, 2007). No exemplo sob análise, após a apresentação do referente (presenting), o Referente 1 é retomado ao longo do texto pelos pronomes pessoais eu, me e mim, pelos pronomes possessivos meu e minha e 24 vezes pela forma elíptica [eu]. Já o Referente 2, que é o foco/assunto do escritor, é retomado por uma grande variedade de termos: a tarefa escolar de aprender as letrinhas (1. 3), seus (1. 3), aquele código aparentemente indecifrável (1. 5-6), aqueles símbolos mágicos (1. 10), a lógica das letras (1. 13), o ambiente mágico da leitura (1. 19), aquele universo das palavras (1. 20), leitura como prática social (23), leitura (1. 26, 89, 90, 98, 100-101), diversas leituras infantis (1. 38), leituras pré-escolares (1. 44), o belo mundo multicolor (1. 51), estas leituras (1. 62), facilidade na leitura (1. 69), na leitura (1. 75), leituras obrigatórias (1. 92-93), ela (1. 99-100), instrumento indispensável (1.103), de leitura (1. 108).

\footnotetext{
${ }^{8}$ Para uma melhor organização da análise dos recursos de IDENTIFICAÇÃO, os trechos do Texto A foram numerados.
} 
Segundo Martin e Rose (2007), um participante também pode ser identificado por meio de uma referência comparativa e referência de posse. Estes dois recursos são usados tanto para apresentar como para recuperar um participante já mencionado no texto.

A referência comparativa é utilizada para comparar referentes distintos de um texto. Por meio deste recurso é possível comparar identidades, a intensidade da qualidade de algo ou a sua quantidade, a posição de um referente em relação ao outro, entre outras coisas.

No Texto, o autor utiliza algumas comparações para auxiliá-lo a descrever sua opinião acerca da importância e a sua relação com a leitura, como no trecho destacado abaixo (02):

(02) $\mathrm{O}$ terceiro ano do Ensino Médio parecia tão chato literariamente falando que muito do que dizia respeito à leitura tornara-se preto e branco, sem prazer e atrativos, ou cinza e sem graça como uma placa de chumbo. (1. 95-97)

No trecho (02), o autor compara a leitura a uma placa de chumbo, com o propósito de destacar a diferença entre a intensidade do colorido da leitura na infância e a sua falta de cor no Ensino Médio.

Por sua vez, em (03), o autor traz a leitura em duas etapas diferentes de sua vida, tentando transmitir para o leitor o quanto a leitura perdeu o colorido, a idealização à medida que foi se tornando uma obrigação.

(03) a leitura tem se reapresentado a mim como quem pede desculpas. Sim, é verdade que ela não é mais tão colorida ou idealizada como antes [...] (1. 98-100)

Observa-se que, nos exemplos (02) e (03), a comparação retoma um "passado colorido" em relação à leitura e apresenta o novo olhar a respeito do referente. Assim, a referência comparativa tem a propriedade de retomar algo, ao mesmo tempo em que apresenta um novo referente, ou, como no exemplo (03), uma nova "versão" de um mesmo referente.

A referência de posse é outro recurso para identificar participantes. Por intermédio do uso do pronome possessivo é possível saber de quem ou o que se está falando. Quando a referência de posse é utilizada, fica evidente que há duas identidades: a identidade do possuidor, que é sempre uma identidade presumida; e a do "objeto" de posse, que pode ter sido mencionado anteriormente ou não. No texto A, os pronomes mеu(s) e minha(s), além de retomarem o Referente 1, inserem 19 novos referentes no texto. Já os pronomes possessivos seu(s) e sua(s) retomam diversificados referentes, e sua ocorrência é bem menor. O Quadro 2 mostra a relação de ocorrências dos pronomes possessivos e que referentes são introduzidos ou retomados por meio deles.

Quadro 2 - Referência de posse: retomada e inserção de referentes.

\begin{tabular}{|l|l|l|}
\hline Referente retomado & Recurso & Referentes inseridos pelo pronome possessivo \\
\hline Referente 1 & meu(s) & $\begin{array}{l}\text { pais } \\
{[\text { livro] preferido }}\end{array}$ \\
\hline
\end{tabular}




\begin{tabular}{|c|c|c|}
\hline & & $\begin{array}{l}\text { objetivo inicial de leitora } \\
\text { olhos curiosos } \\
\text { conhecimento textual } \\
\text { mundo leitor } \\
\text { conflitos de pré-adolescente } \\
\text { senso } \\
\text { objetivos de leitura } \\
\text { mundo novo quase adulto de leitura }\end{array}$ \\
\hline Referente 1 & $\operatorname{minha}(\mathrm{s})$ & $\begin{array}{l}\text { caminhada na leitura } \\
\text { pequenas mãozinhas } \\
\text { fase } \\
\text { professora } \\
\text { mente } \\
\text { curiosidade } \\
\text { interação com o texto } \\
\text { cabeça } \\
\text { infância }\end{array}$ \\
\hline Referente 2 & seus & Sons \\
\hline signos & seu & significado \\
\hline gente de toda parte do planeta & seus & conflitos \\
\hline livros & suas & histórias \\
\hline Gêneros textuais & suas & estruturas e formas de discurso \\
\hline menina abastada & sua & riqueza \\
\hline leitor & $\operatorname{sua}(\mathrm{s})$ & $\begin{array}{l}\text { exposição a todo tipo de texto } \\
\text { expectativas em relação aos textos }\end{array}$ \\
\hline texto & sua & compreensão \\
\hline
\end{tabular}

Fonte: as autoras

O Referente 1 insere no texto diversos participantes ligados à sua identidade, inclusive partes do próprio referente como mãozinhas, mente, cabeça, olhos curiosos, que, segundo Martin e Rose (2007), também podem ser apresentadas e presumidas pela referência de posse.

Além de pessoas e objetos, é possível recuperar as coisas que as pessoas dizem, utilizando-se principalmente os pronomes demonstrativos. Este recurso de rastreamento é chamado por Martin e Rose (2007) de referência de texto, e quanto ao seu uso, os autores destacam a vantagem de poder "empacotar" certas informações, tornando-as mais gerenciáveis. O texto Do colorido prazer à necessidade (l.01) é uma narrativa pessoal, um Memorial de Leitura, mas que contém algumas citações de autores que tratam sobre a leitura, assim, há ocorrência de recuperação, através de pronomes demonstrativos, tanto de falas do próprio autor como de fala dos autores citados. Assim, as referências de texto são expostas no Quadro 3 que segue:

Quadro 3 - Referência de texto.

\begin{tabular}{|l|l|}
\hline Recurso utilizado & Referência de texto (Informação empacotada) \\
\hline essas ações & - a decifração do escrito e a compreensão do conteúdo do texto \\
\hline isso & - o prazer e a descoberta \\
& - conhecer alguns gêneros textuais, suas estruturas e formas de discurso a mim \\
& $\begin{array}{l}\text { apresentados } \\
\text { - minha professora de português optou por fazer trabalhos com as turmas abordando } \\
\text { diferentes gêneros textuais: poesias, publicidades, poemas visuais, receitas, } \\
\text { crônicas, notícias, cartas, diários e entre outros. }\end{array}$ \\
\hline
\end{tabular}




\begin{tabular}{|l|l|}
\hline estes pontos & - da trama, dos aspectos linguísticos e abordagem histórica dos livros \\
\hline Estas leituras & $\begin{array}{l}\text { - Judy Moody, de Megan McDonald, O Diário da Princesa, de Meg Cabot, A } \\
\text { Princesinha, de Frances Burnett. Muitos outros títulos. }\end{array}$ \\
\hline isto & $\begin{array}{l}\text { - estava começando a tornar-me apta para realizar essas ações: finalmente eu } \\
\text { entendera a lógica das letras e conseguia decodificá-las } \\
\text { - o ambiente mágico da leitura havia tomado forma para mim } \\
\text { - o incentivo dado neste quesito pelas professoras era entrelaçado a uma obrigação } \\
\text { por elas imposta }\end{array}$ \\
\hline $\begin{array}{l}\text { naquilo que } \\
\text { Kleiman fala }\end{array}$ & $\begin{array}{l}\text { - fazer da leitura uma atividade caracterizada pelo engajamento e uso do } \\
\text { conhecimento, em vez de uma mera recepção passiva }\end{array}$ \\
\hline
\end{tabular}

Fonte: as autoras

Os termos essas ações, isso, estes pontos, estas leituras, isto e naquilo que Kleiman fala são expressões que retomam uma ideia exposta no texto e que as sintetizam para depois criar novos significados a partir delas, possibilitando a expansão do texto.

Para uma melhor visualização, os tipos de referências apresentados por Martin e Rose (2007) e os recursos utilizados para a realização do rastreamento de identidades no texto Do colorido prazer à necessidade, são expostos no Quadro 4.

Quadro 4 - Resumo dos recursos referenciais utilizados no texto A.

\begin{tabular}{|l|l|}
\hline Tipo & Recursos \\
\hline apresentação & $\mathrm{a}$, um, num, uma, numa \\
\hline presunção & Eu, [eu], me, mim, a, o, seus, aquele (s), estas, ela \\
\hline posse & meu, meus, minha, minhas, seu, seus, sua, suas \\
\hline comparação & como, mais, tão - como \\
\hline referência textual & essas, isso, estes, estas, isto, naquilo \\
\hline
\end{tabular}

Fonte: as autoras

Quando se tem uma referência presumida, em textos escritos, em geral, busca-se essa referência no próprio texto, como foi possível observar no Texto A. Segundo Martin e Rose (2007), na maior parte das vezes, encontra-se a identidade buscada "olhando para trás". No entanto, é possível recuperar essa identidade olhando-se para frente e, em alguns casos fora do texto, como é possível observar nos exemplos que seguem.

Ao se procurar a referência no texto, pode-se encontrar uma referência anafórica, que, como afirmam os autores, é o tipo mais usado e faz alusão a algo já mencionado anteriormente no texto. O trecho (04), retirado do Texto A, traz dois exemplos de referência anafórica.

(04) $\mathrm{O}$ incentivo dado neste quesito pelas professoras era entrelaçado a uma obrigação por elas imposta, mas eu não percebia isto. (1. 27-28)

No exemplo (04), o pronome elas, destacado em negrito, retoma anaforicamente o referente professoras. De modo igual, o pronome demonstrativo isto, sublinhado no mesmo exemplo, retoma o trecho $O$ incentivo dado neste quesito pelas professoras era entrelaçado a uma obrigação por elas imposta, também sublinhado. 
Outra forma de recuperar uma referência é por meio do uso de catáfora. A catáfora é um tipo de referência que faz menção a um termo subsequente, ou seja, refere-se a algo que será mencionado posteriormente. Desta forma, para descobrir o significado de determinado termo, temos que "olhar para frente". O trecho (05) é exemplo de uma referência catafórica, uma vez que o pronome demonstrativo naquilo faz referência a algo que será dito posteriormente.

(05)Estava cada vez mais engajada naquilo que Kleiman fala sobre "fazer da leitura uma atividade caracterizada pelo engajamento e uso do conhecimento, em vez de uma mera recepção passiva" (1. 82-84)

Nos trechos (04) e (05), a referência se localizava no entorno textual. No entanto, uma referência pode estar fora do texto verbal, sendo classificada em dois tipos: homófora, quando o referente está na cultura compartilhada pelo escritor e pelo leitor; e exófora, que está relacionada ao contexto de situação. Esta última é, segundo Martin e Rose (2007), a mais difícil de relacionar aos elementos textuais, uma vez que os textos escritos são autossuficientes, não necessitando de ilustrações para a compreensão do seu significado. Tal referência não foi encontrada no texto sob análise. No exemplo (06) a seguir, pode-se observar um caso de referência homófora:

(06) Quando criança, eu não vi a tarefa escolar de aprender as letrinhas e os seus sons como enfadonha ou entediante, ou algo que poderia parecer repetitivo por parte das professoras. (1. 3-5)

No trecho (06), o referente Leitura é inserido pela primeira vez no texto de forma definida pela expressão a tarefa escolar de aprender as letrinhas. Tal possibilidade decorre do fato de que autor e leitor compartilham do conhecimento desta tarefa de aprender as letras, que também foi chamada posteriormente de leitura no texto sob análise. Assim, conclui-se que a identidade do referente se encontra no contexto de cultura. O mesmo ocorre no trecho (07), em que o conhecimento compartilhado são as etapas de ensino percorridas por um estudante em contexto brasileiro. O referente Ensino Fundamental é inserido presumindo-se um conhecimento anterior, que não está no texto, mas no contexto de cultura em que estão inseridos escritor e leitor.

(07) Conforme avancei no Ensino Fundamental, me afastei do campo infantil e fui iniciada, através da escola e de amigos, na literatura infanto-juvenil. (1. 53-54)

O uso do pronome definido no trecho (07), para apresentar o referente Ensino Fundamental, justifica-se então pelo fato de o leitor poder buscar este referente em sua cultura.

A Figura 2 mostra os possíveis lugares em que é possível encontrar uma identidade presumida. 


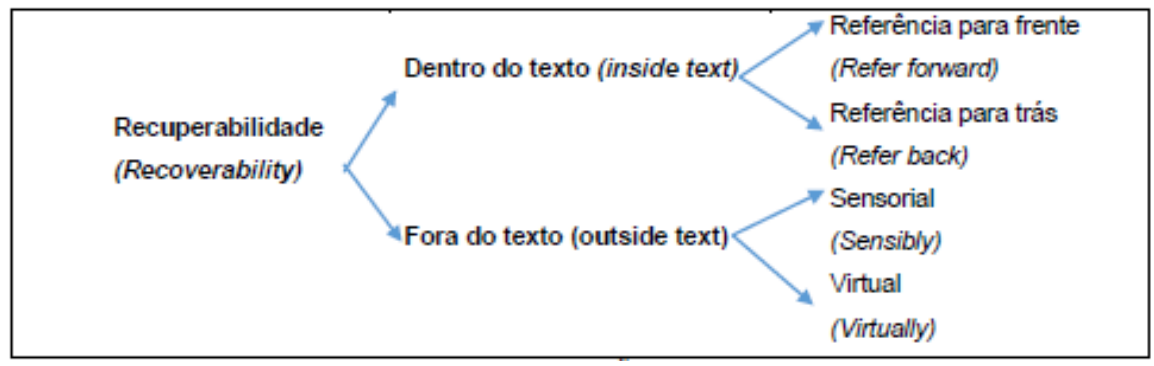

Figura 2 - Recuperação de identidades.

Outra forma de fazer referência, segundo Martin e Rose (2007), é a referência indireta, também chamada pelos autores de referência ponte. Tal recurso é menos comum que os citados anteriormente e consiste em referenciar algo de forma indireta, ou seja, o participante é presumido sem ter sido mencionado diretamente. O trecho (08) demonstra o uso da referência indireta.

(08) Quando criança, eu não vi a tarefa escolar de aprender as letrinhas e os seus sons como enfadonha ou entediante, ou algo que poderia parecer repetitivo por parte das professoras. Pelo contrário: $\varnothing[\mathrm{eu}]$ quis poder entender o mais rápido possível aquele código aparentemente indecifrável que meus pais compreendiam; $\varnothing[\mathrm{eu}]$ ansiei por aprender a ler. Assim, $\varnothing[\mathrm{eu}]$ encarei as letras e as palavras como amigas a serem conquistadas, de modo que não fossem apenas desenhos. $\varnothing[\mathrm{eu}]$ Lembro de responder empolgadamente à professora da pré-escola o som que cada letrinha fazia; eu estava impaciente para finalmente decifrar aqueles símbolos que pareciam mágicos!

Segundo Britto (2012), as ações básicas de ler são a decifração do escrito e a compreensão do conteúdo do texto. Aos cinco anos, eu estava começando a tornar-me apta para realizar essas ações: finalmente eu entendera a lógica das letras e $\varnothing[\mathrm{eu}]$ conseguia decodificá-las (isto é, entender os sons produzidos por aqueles signos, e consequentemente, seu significado). Quando as tais letras do alfabeto ganharam sentido para mim, o mundo ficou mais doce e colorido: $\varnothing$ [eu] passei a escrever num diário cor-de-rosa e podia ler os livros que a professora lia para turma. (1.03-17)

Em (08), a palavra livro é inserida apenas na última linha. No entanto, antes disso fala-se de leitura, letras e outros termos que levam à presunção da existência de livros, que acabam por ser inseridos por uma expressão definida, uma vez que sua existência já está presumida.

Enfim, os recursos apontam para a IDENTIFICAÇÃO e rastreamentos de referentes que, segundo Sippert (2017, p. 77), "sugerem uma representação extensional de referentes do mundo", permitindo uma importante relação com a coesão e coerência textual. A análise demonstra que, através dos recursos utilizados para inserir e retomar cada um dos referentes, o escritor manteve a coesão textual. É interessante destacar que para cada um dos referentes foram utilizados recursos distintos, ainda que para alcançar um mesmo fim. A análise realizada revela como é realizado o rastreamento de participantes em um texto em Língua Portuguesa. Ainda que não seja possível observar, olhando apenas para um texto, se é um padrão que se mantém, pode-se afirmar que foram identificadas a quem ou a que uma expressão se refere e as suas diferentes formas de rastreamento de participantes no texto. 


\section{Considerações finais}

Os resultados mostraram o funcionamento da IDENTIFICAÇÃO em um texto, indicando ser um recurso textual utilizado para acompanhar como as pessoas e objetos foram inseridos e rastreados ao longo de um exemplo: o Memorial de Leitura. Verificou-se que os principais referentes (Referente 1 e Referente 2) do texto analisado, foram retomados ao longo do texto e se tratam de elementos que mantêm o olhar do leitor, em torno dos quais as informações novas giram. Resumidamente, no Quadro 5, destacados em negrito, é possível observar o Referente 1 - Eu Narrador - como o eixo a partir do qual vão sendo dadas as novas informações em uma das Etapas do Texto A:

Quadro 5 - Rastreamento do Referente 1.

\begin{tabular}{|l|l|l|}
\hline Quando criança & Eu & $\begin{array}{l}\text { não vi a tarefa escolar de aprender } \\
\text { as letrinhas e os seus sons como } \\
\text { enfadonha ou entediante, ou algo } \\
\text { que poderia parecer repetitivo por } \\
\text { parte das professoras }\end{array}$ \\
\hline & Pelo contrário: $[\mathbf{e u}]$ & $\begin{array}{l}\text { quis poder entender o mais rápido } \\
\text { possível aquele código } \\
\text { aparentemente indecifrável }\end{array}$ \\
\hline & meus pais & Compreendiam [o código] \\
\hline & Assim, $[\mathbf{e u}]$ & $\begin{array}{l}\text { ansiei por aprender a ler } \\
\text { encarei as letras e as palavras como } \\
\text { amigas a serem conquistadas, de } \\
\text { modo que não fossem apenas } \\
\text { desenhos }\end{array}$ \\
\hline & {$\left[\begin{array}{l}\text { Lembro de responder } \\
\text { empolgadamente à professora da } \\
\text { pré-escola o som que cada letrinha } \\
\text { fazia }\end{array}\right.$} \\
\hline & $\begin{array}{l}\text { estava impaciente para finalmente } \\
\text { decifrar aqueles símbolos que } \\
\text { pareciam mágicos! }\end{array}$ \\
\hline
\end{tabular}

Fonte: as autoras.

A manutenção destes elementos permite que o escritor possa desenvolver o fluxo do discurso sem perder a coerência, sem fugir do campo do discurso. Assim, podem-se entender esses referentes como o eixo central em torno do qual o texto se desenvolve. Na Figura 3, a seta central representa o Referente 1 do Texto A, em torno do qual as informações giram, relação que permite desenvolvimento do texto. 


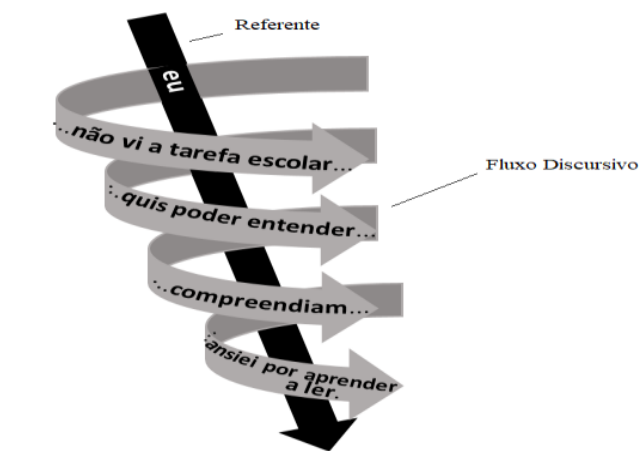

Figura 3 - O rastreamento no fluxo discursivo.

Uma análise com tratamento quantitativo dos dados e com um corpus mais numeroso poderia contribuir com padrões existentes nos textos e evidenciar a constituição do gênero Memorial de Leitura em contexto acadêmico brasileiro. Tal possibilidade, embora não tenha sido o propósito desta pesquisa pela sua natureza e alcance, poderia elevar a importância deste trabalho, que objetivou um olhar qualitativo para o texto, buscando analisar sua organização semântico-discursiva, dentro de um contexto de uso da língua.

\section{REFERÊNCIAS}

DÖRNYEI, Z. Research Methods in Applied Linguistics: Quantitative, Qualitative, and Mixed Methodologies. Oxford: Oxford University Press, 2007.

FUZER, C.; CABRAL, S. R. S. Introdução à Gramática Sistêmico-Funcional em Lingua Portuguesa. 1. ed. Campinas: Mercado de Letras, 2014.

GHIO, E.; FERNÁNDEZ, M. D. Lingüística Sistémico Funcional: Aplicaciones a la Lengua Espanhola. 1. ed. Santa Fe: Universidad Nacional del Litoral, Waldhuter Editores, 2008.

HALLIDAY, M. A. K. El Lenguaje como Semiótica Social: La interpretación social del lenguaje y del significado. Tradução: Jorge Ferreiro Santana. 1. ed. Buenos Aires: Argentina Fondo de Cultura Económica de Argentina S.A., 2001.

Sobre la "arquitectura" del lenguaje humano. In: GHIO, E.; NAVARRO, F (comp.). Obras esenciales de MAK Halliday. Tradução: Annabelle Lukin. Santa Fe: Ediciones UNL, 2017.

HALLIDAY, M. A. K.; MATTHIESSEN, C. M. I. M. An Introduction to Functional Grammar. 4. ed. London: Arnold, a member of the Hodder Headline Group, 2014.

HALLIDAY, M. A. K.; HASAN, R. Cohesion in spoken and written English. London: Longman, 1976. 
Language, context, and text: aspects of language in a social-semiotic perspective. Oxford: Oxford University Press, 1985.

LEITURA E PRODUÇÃO TEXTUAL. Banco de dados composto por textos de alunos do curso de Letras da UFRGS. [S.1.], 2014-2018. Disponível em: http://textosletras1sem.blogspot.com/. Acesso em: 30 abr. 2018.

LEITURA: do colorido prazer à necessidade. In: Leitura e Produção Textual. [S.1.], 2014. Disponível em: http://textosletras1sem.blogspot.com/2014/06/leitura-do-coloridoprazer-necessidade_29.html. Acesso em: 30 abr. 2018.

MARTIN, J. R. La Gramática se reúne com el género: Reflexiones sobre la Escuela de Sydney. Dep. de Lingüística, Universidad de Sydney. Inaugural Lecture Sydney University Arts Association, 2000.

MARTIN, J. R.; ROSE, D. Working with Discourse: Meaning beyond the clause. 2. ed. London: Continuum, 2007.

MARTÍNEZ LIROLA, M. Aspectos esenciales de la gramática sistémica funcional. Universidad de Alicante. Servicio de Publicaciones, Alicante, 2007.

MUNIZ DA SILVA, E. C. Gêneros na teoria sistêmico-funcional. Delta-

Documentação de estudos em linguística teórica e aplicada da PUCSP, São Paulo, v. 34, p. 305-330, 2018.

ROTTAVA, L. A construção de portfólio para compreensão do processo de escrita em contexto acadêmico. In: II Seminário Internacional de Língua, Literatura e Processos Culturais. Caxias do Sul, RS, 2014. p. 914-920.

A metáfora gramatical e seus efeitos no texto acadêmico: um estudo a partir do gênero memorial de leitura. Comunicação apresentada no XIII ALSFAL, 06 a 10 de noviembre de 2017, Universidad Nacional de Córdoba. Córdoba, AR.

SIPPERT, L. Análise da progressão textual e da estrutura temática em resenhas de alunos do Ensino Superior: um olhar sistêmico-funcional aliado à perspectiva sociointeracionista. 2017. Tese (Doutorado em Letras) - Instituto de Letras, UFRGS, Porto Alegre, RS, 2017.

VIAN, O. J.; IKEDA, S. N. A análise do discurso pela perspectiva sistêmico-funcional. In: LEFFA, V. (org.) Pesquisa em Linguística Aplicada: Temas e Métodos. Pelotas: Educat, 2006. p. 31-69.

VIAN, O. J.; MENDES, W. V. O sistema de conjunção em textos acadêmicos: os mecanismos de sequenciamento e de explicação. Letras, Santa Maria, v. 25, n. 50, p. 163-186, jan./jun. 2015. 